\title{
Prediction and Assessment of Marine Pollution Risk from Ships Based on Statistical Analysis Probability Model
}

\author{
Hejun Geng, Xiaobin Jiang, Deling Wang, Jie Li* \\ Merchant Marine College, Shanghai Maritime University, Shanghai, China \\ Email address: \\ genghj@shmtu.edu.cn (Hejun Geng), xbjiang@shmtu.edu.cn (Xiaobin Jiang),dlwang@shmtu.edu.cn (Deling Wang), \\ lijie@shmtu.edu.cn (Jie Li) \\ ${ }^{*}$ Corresponding author
}

\section{To cite this article:}

Hejun Geng, Xiaobin Jiang, Deling Wang, Jie Li. Prediction and Assessment of Marine Pollution Risk from Ships Based on Statistical Analysis Probability Model. American Journal of Traffic and Transportation Engineering. Vol. 6, No. 2, 2021, pp. 34-42.

doi: $10.11648 /$ j.ajtte.20210602.11

Received: March 17, 2021; Accepted: March 29, 2021; Published: April 7, 2021

\begin{abstract}
In recent years, with the rapid development of the national marine economy, maritime cargo transportation has continued to increase. In particular, the transportation volume of oil products and hazardous chemicals is increasing rapidly, and the risk of pollution to the water environment caused by ships and related operations is increasing, and marine oil spill accidents occur from time to time. Once a ship spills oil, the oil spilled on the sea migrates and spreads in the ocean as impacted by wind and tidal currents, thereby exerting adverse effects on the surrounding marine environment. As guided by sustainable development strategy, all mankind have developed a consensus of natural ecological protection, and effective prevention and treatment of ship pollution are suggested to show critical significance. Thus, given the development status and historical accidents of a specific water area, this study employs a method based on probability statistics to predict the risk of marine pollution and explore the effective prevention and countermeasures for the pollution. Conducted oil spill risk assessment on Ningbo Guanbao Terminal. Determine the risk value of oil spill accidents in each port area in the area, and provide support for the site selection of the oil spill emergency equipment warehouse in the port waters. The results will be conducive to guiding ship marine oil spill risk management.
\end{abstract}

Keywords: Marine Pollution, Ships, Risk Assessment, Marine Accident, Risk Management

\section{Introduction}

Overall, ship pollution mainly refers to the irreversible pollution of the marine environment that is attributed to the leakage of fuel and cargo carried by ships for subjective and objective factors. Ship pollution can significantly jeopardize society, which is inconsistent with the concept of sustainable development of human society. Thus, to maintain green ecology, it is critical to effectively prevent and control ship pollution. In the case of ship pollution, an oil film will be formed on the sea, thereby blocking the oxygen exchange between sea water and air. Meantime, sunlight is weakened, and a series of biological chain reactions are caused. Moreover, since water exhibits fluidity, ship pollution may spread to multiple areas, instead of being fixed in a certain area. In severe cases, harmful substances in the air may increase, thereby irreversibly affecting the natural ecology.
Many scholars have conducted research on oil spill. The United States enacted the "River Oil Pollution Prevention Act" as early as 1924 [1]. However, the systematic research on oil spill risks emerged after serious oil spill accidents (e.g., "Torrey Canyon" (Torrey Canyon)). Guan discussed the main inducement of oil spill from ships, expounds the methods of oil spill risk assessment at home and abroad, and analyzed the present key problems of oil spill risk assessment from the ship itself and human environment [2]. Nelson, J. R. use a kriging interpolation method to model the oiled coastline as a continuous surface to better match actual oil landfall observed in reality and then use it to provide a more robust estimation of the smaller scale impacts [3]. Ekpenyong et al study on the impact of oil spill on sea foods of safety in the Nigerian environment [4]. Na, Song-Jin analyzes all 93 documents related to the ship's sinking and the eventual cleanup, confirming delays in administrative decision-making on the 
removal, and identifies factors that influenced this delay [5].

The National Emergency Response Plan for Maritime Search and Rescue was released in 2006 to build a national emergency response mechanism for maritime search and rescue [6]. On March $8^{\text {th }}$, 2018, the "National Major Marine Oil Spill Emergency Response Plan" (the "Plan") [7] was reviewed and issued by the National Inter-Ministerial Joint Conference on Major Marine Oil Spill Emergency Response. In addition, the National Major Marine Oil Spill Response Capability Building Plan (2015-2020) [8], China's first special plan for oil spill response capabilities, integrating the central and the local, government and enterprise, as well as multi-sectoral forces, was approved by the State Council in 2016 and jointly issued by the Ministry of Transport and the National Development and Reform Commission. In terms of research on port terminals, large oil tanker terminals are recognized as the focus of risk assessment research for the high oil spill risks facing them. Extensive studies have been conducted on the oil spill risks of different ports and terminals across the country (e.g., Ningbo Port [9], Dalian Xingang [10], and Yantai Port [11]).

In this paper, with Ningbo Guanbao Wharf as an example, by comprehensively considering various factors, the probability of marine oil spill pollution accidents by ships at the port is predicted by exploiting the statistics regarding the current status of the port. On that basis, the paper attempts to assess the risk of marine oil spill accidents. Given emergency policy, emergency personnel, and emergency equipment, the countermeasures for reducing the consequences of pollution hazards were proposed, respectively. In the event of an oil spill, reasonable and effective emergency measures should be taken immediately to reduce the impact of the oil spill on the environment, productions and lives.

\section{Port Status Analysis}

\subsection{Current Status of Port Water Transport Throughput}

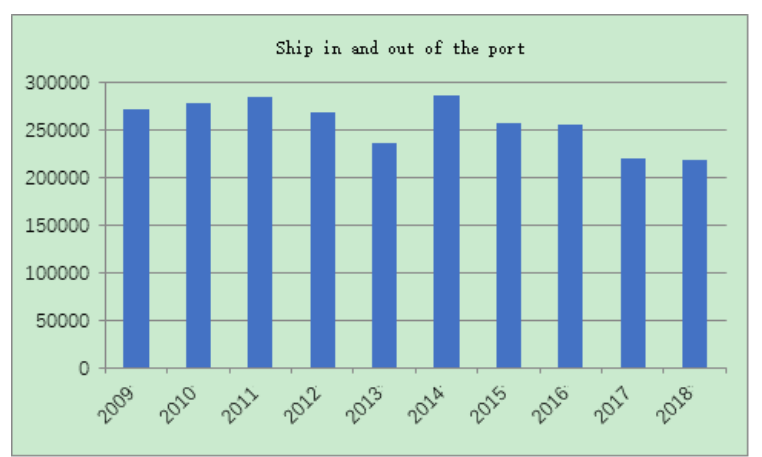

Figure 1. Changes in the number of ships entering and leaving the port in Ningbo Port from 2009 to 2018.

As suggested by statistics, the overall number of sea-going vessels entering and leaving Ningbo port has been basically stable over the past decade, with more than 20000 vessels a year. From 2009 to 2011, the number of vessels increased slightly. In the following two years, the number of seagoing vessels in and out of Ningbo port decreased significantly. However, in 2014 it quickly rose to the highest value in the past decade, and then declined. The statistics of inbound and outbound vessels are shown in Figure 1.

Overall, the cargo throughput of Ningbo Port fluctuated from 2009 to 2018; it reached a small peak in 2014, with a throughput of 526 million tons, and then declined slightly; afterward, it started to rise in 2017 and was peaked at 577 million tons in 2018 (Figure 2).

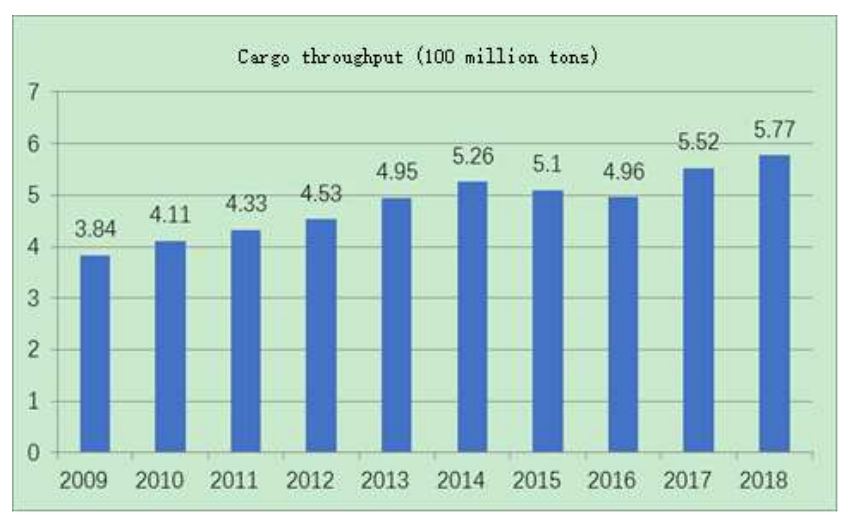

Figure 2. Cargo throughput statistics of Ningbo Port from 2009 to 2018.

From 2009 to 2018, there is no obvious positive correlation between the cargo throughput of Ningbo port and the number of ships entering and leaving the port. The main reason for the lack of positive correlation is related to the size and type of ships in that year. From the analysis of the above two statistical data, it can be seen that the size of sea going ships entering and leaving Ningbo port has increased significantly, so that the port throughput can grow steadily with the number of ships decreasing.

\subsection{Statistics and Analysis of Port Ship Accidents}

\subsubsection{Statistics and Analysis of Ship Traffic Accidents}

As indicated from the available data, the statistics of accidents above the ship traffic level in Ningbo Port Area from 2009 to 2018 have been conducted (Figure 3).

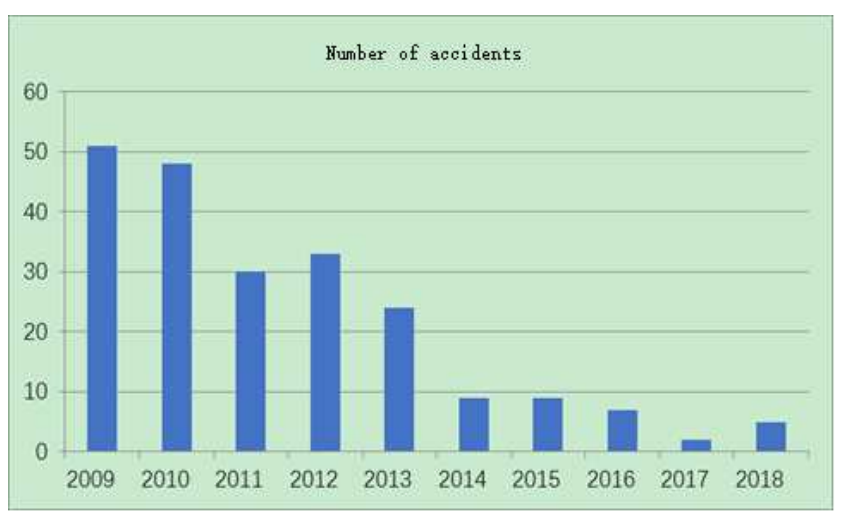

Figure 3. The number of ship traffic accidents in Ningbo Port Area from 2009 to 2018 .

Overall, 218 accidents above the ship traffic level occurred in Ningbo Port Area from 2009 to 2018. The number of accidents decreased, with the minimal number of accidents in 2017 reaching 2. By complying with the classification of 
accident causes, accidents can fall to operational accidents and marine accidents. Moreover, operational accidents can be split as fuel refueling, other operations, and illegal emissions in accordance with the accident. Generally, marine accidents are classified into collisions, strandings, touches, rocking, fire and explosion, wind and wave disasters, as well as self-sinking. To be specific, there existed 122 collision accidents (56\%), 43 self-sinking accidents (19.7\%), and 19 collision accidents $(8.7 \%)$. The main cause of the accident collision can be therefore revealed. Table 1 lists the statistical classification of ship traffic accidents.

Table 1. Classification statistics of ship traffic accidents in Ningbo Port Area from 2009 to 2018.

\begin{tabular}{|c|c|c|c|c|c|c|c|c|c|}
\hline Year & Collision & Stranding & Rocking & Touching & Fire & Storm & Sinking & Other & Total \\
\hline 2009 & 31 & 1 & 1 & 4 & 2 & 1 & 11 & 0 & 51 \\
\hline 2010 & 38 & 1 & 1 & 1 & 1 & 0 & 5 & 1 & 48 \\
\hline 2011 & 19 & 0 & 3 & 4 & 0 & 0 & 4 & 0 & 30 \\
\hline 2012 & 9 & 4 & 4 & 4 & 0 & 0 & 12 & 0 & 33 \\
\hline 2013 & 8 & 0 & 0 & 3 & 0 & 5 & 5 & 3 & 24 \\
\hline 2014 & 4 & 1 & 0 & 1 & 0 & 0 & 3 & 0 & 9 \\
\hline 2016 & 5 & 0 & 0 & 1 & 0 & 0 & 0 & 1 & 7 \\
\hline 2017 & 1 & 0 & 0 & 0 & 0 & 0 & 1 & 0 & 2 \\
\hline 2018 & 4 & 0 & 0 & 0 & 0 & 0 & 0 & 1 & 5 \\
\hline Total & 122 & 7 & 9 & 19 & 3 & 6 & 43 & 9 & 218 \\
\hline
\end{tabular}

From 2009 to 2018, the total number of ships entering and leaving the port was 2,571,799, and the total cargo throughput reached 4.753 billion tons. Table 2 lists the statistical results of the frequency of ship traffic accidents in Ningbo Port.

Table 2. Frequency of ship traffic accidents from 2009 to 2018.

\begin{tabular}{llll}
\hline Type of accident & $\begin{array}{l}\text { Number of accident } \\
\text { (incidents) }\end{array}$ & $\begin{array}{l}\text { Frequency of occurrence } \\
\text { (incidents/year) }\end{array}$ \\
\hline \multirow{4}{*}{ Traffic } & Collision & 122 & 12.2 \\
& Stranding & 43 & 4.3 \\
accident & Touch & 19 & 1.9 \\
& Hit the rocks & 9 & 0.9 \\
& Fire & 3 & 0.3 \\
& Storm & 6 & 0.6 \\
& Sink & 43 & 4.3 \\
& Other & 9 & 0.9 \\
\hline
\end{tabular}

\subsubsection{Statistics and Analysis of Ship Pollution Accidents}

In accordance with statistics, 10 ship oil spill pollution accidents totally occurred from 2009 to 2018. Following the classification statistics of the leakage of pollution accidents, the specific conditions can be determined (Table 3).

Table 3. Statistics of ship oil pollution accidents in Ningbo Port Area from 2009 to 2018.

\begin{tabular}{lll}
\hline Year & Accident (incidents) & Oil spill (tons) \\
\hline 2009 & 4 & 0.18 \\
2010 & 4 & 0.5 \\
2011 & 1 & 121 (Liquid caustic soda) \\
2014 & 1 & 0.05 \\
2015 & 0 & 0 \\
2016 & 0 & 0 \\
2017 & 0 & 0 \\
2018 & 0 & 0 \\
Total & 10 & $121.73(0.73$ oil spill, 121 liquid caustic soda) \\
\hline
\end{tabular}

Specific to accident types, though a relatively small number of ship pollution accidents occur, and the oil spill volume caused is relatively large, which should be specifically concerned. The types of pollution accidents on ships largely consist of improper operation, equipment failure, illegal discharge, collisions, stranding, or touches of ships in navigation channels, anchorages, and wharves. By complying with the classification standards of ship pollution accidents stipulated in the Regulations on the Prevention and Control of Ship Pollution to the Marine Environment, ship pollution accidents fall to particularly severe ship pollution accidents, major ship pollution accidents, larger ship pollution accidents, as well as general ship pollution accidents. A ship pollution accident with less than 100 tons of oil spilled or triggering a direct economic loss of less than 50 million RMB refers to a general ship pollution accident. Over the past decade, ship pollution accidents in Ningbo waters have been overall general accidents; only one oil spill from 10 to 49 tons occurred; other accidents had oil spills of less than 10 tons. As calculated based on the statistical data of throughput frequency (set to 3.85 million tons/year), the frequency of ship traffic accidents during the port operation period is nearly 0.17 per year, of which ship oil spill pollution accidents have an approximate frequency of $8.1 \times 10^{-4}$ per year.

\section{Pollution Probability Prediction of Marine Oil Spill Accidents}

\subsection{Wharf Traffic Forecast}

The terminal primarily receives and unloads wood chips, coal, wood pulp (piece cargo), as well as limestone (calcium carbonate), capable of handling 3.85 million tons per year. The largest ship type designed refers to a 50,000-ton bulk carrier (the hydraulic structure of the wharf designed for berthing 70,000-ton bulk carriers). Table 4 lists the forecast of cargo throughput and flow direction of Ningbo Guanbao Terminal Co., Ltd. 
Table 4. Cargo throughput of Ningbo Guanbao Terminal Co., Ltd.

\begin{tabular}{llll}
\hline Type of goods & $\begin{array}{l}\text { Incoming port } \\
(\mathbf{1 0 , 0 0 0} \text { t/a) }\end{array}$ & $\begin{array}{l}\text { Departing } \\
(\mathbf{1 0 , 0 0 0} \text { t/a) }\end{array}$ & $\begin{array}{l}\text { Total }(\mathbf{1 0 , 0 0 0} \\
\text { t/a) }\end{array}$ \\
\hline Wood chips & 200 & $/$ & 200 \\
coal & 78 & $/$ & 78 \\
Wood pulp & 59 & $/$ & 59 \\
limestone & 48 & $/$ & 48 \\
Total & 385 & $/$ & 385 \\
\hline
\end{tabular}

With the forecast method of ship traffic flow in the newly built wharf, the annual ship traffic flow $(N)$ of $n$ berths in the wharf is expressed as:

$$
N=\sum_{i=1}^{n} \frac{2 P_{i}}{w_{i} k_{i} Q_{i}}
$$

where $P_{i}$ denotes the designed passing capacity for the $i$-th berth year; $Q_{i}$ expresses the designed ship-type ship deadweight for the $i$-th berth; $w_{i}$ denotes the design coefficient for the $i$-th berth; $k_{i}$ represents the design ship load factor for the $i$-th berth; ${ }_{\mathrm{i}}$ is the number of dock berths.

After the investigation, $P_{\mathrm{i}}$ is taken as 3.85 million tons; $Q_{i}$ is 0.1 for the 10,000-ton ship type coefficient $w$; the 15,000 -ton ship type coefficient $w$ is 0.1 ; the 50,000-ton ship type coefficient $w$ is 0.2 ; the average cargo capacity of the ship is $90 \%$ of the full load, i.e., $\mathrm{k}$ is taken as 0.9 . Subsequently, the flow of ships at this terminal is about 856 vessels per year.

\subsection{Probability Prediction of Pollution Accidents in Nearby Seas}

\subsubsection{Probability Distribution of Pollution Accidents in Nearby Seas}

Under a range of flow field and wind field conditions, after an oil spill accident occurs at a known location, the arrival location turns out to be different. Accordingly, stochastic simulation statistics are adopted to predict the probability and consequences of pollution by complying with the technical requirements of the "Guidelines". Given the set location of the oil spill of the marine accident, the turning point of the channel is taken to simulate the drift and diffusion trajectory of a combination of random scenarios for $48 \mathrm{~h}$. The statistical probability data of the wind field from 2017 to 2018 are randomly selected, and the flow field data are taken from the simulation results of the ocean dynamic model. Next, 300 simulation experiments are performed, and the number of times of oil film drift of each grid during each accident simulation is recorded. Lastly, based on the statistical results, the probability distribution of pollution in the nearby sea area after the occurrence of the oil spill is obtained (Figure 4). This figure indicates that under the random wind field and flow field data, the probability of impact of the same location on different water areas is different.

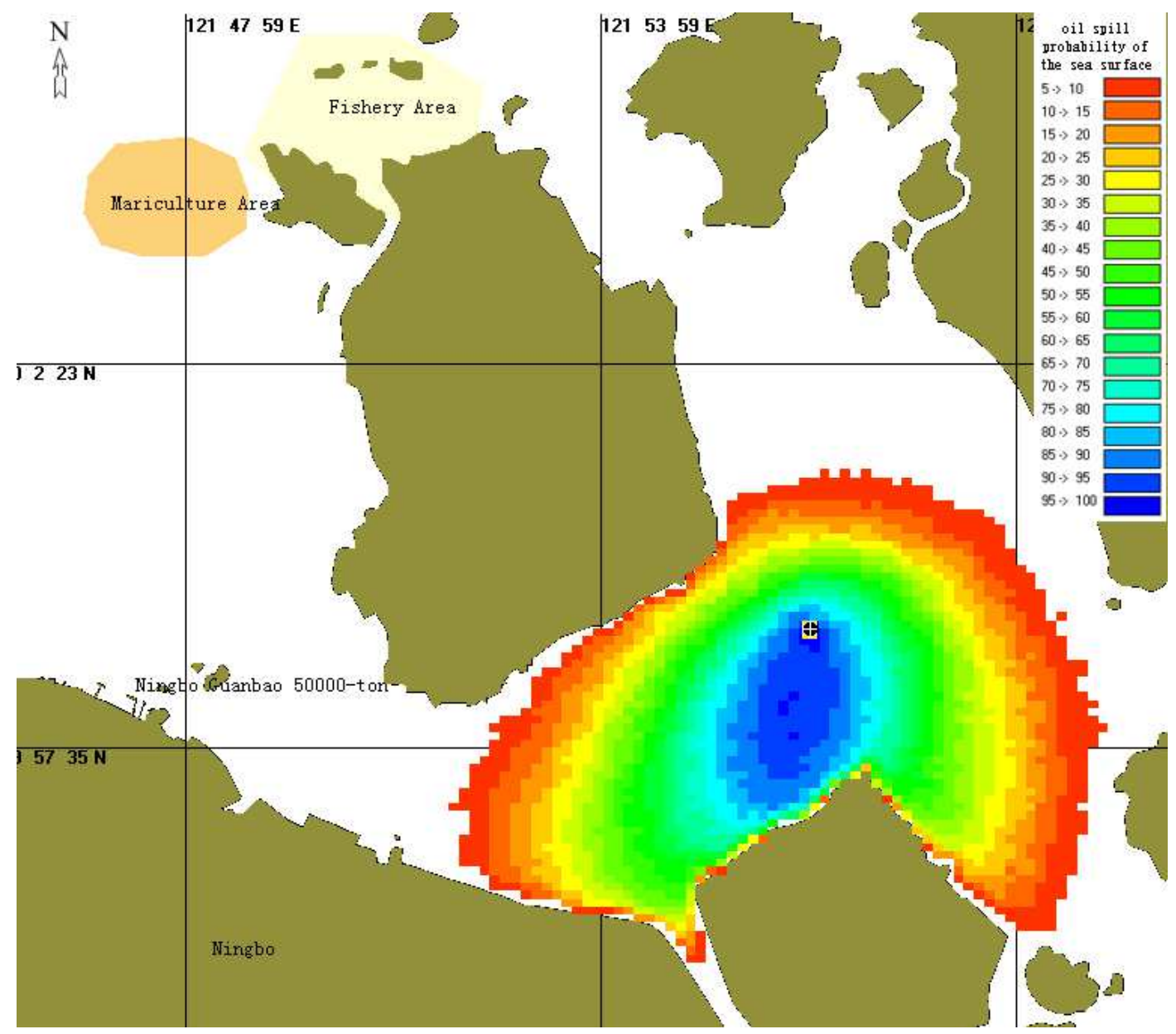

Figure 4. Probability distribution of oil spill pollution at the turning point of the channel. 


\subsubsection{Analysis of Oil Spilled in Ship Pollution Accident}

1) The most likely operational ship oil spill

The leakage volume of the most likely operational ship pollution accident at a wharf is predicted with the second method presented in the "Guidelines", i.e., closing the pump valve or correcting the oil spill volume in $3 \mathrm{~min}$. For a 50,000-ton bulk carrier, the usual refueling speed of a bunker is $500 \mathrm{~m}^{3} / \mathrm{h}$, and the fuel oil density is $0.991 \mathrm{t} / \mathrm{m}^{3}$. Next, the spilled oil volume corrected by closing the pump valve for 3 min reaches $(3 \div 60 \times 500) \times 0.99=24.7 \mathrm{t}$. For safety considerations, the most likely operational ship pollution is predicted as $25.0 \mathrm{t}$, which largely occurs in ship refueling operations at anchorages or in the waters in front of the wharf.

2) The most likely oil spill from a shipwrecked ship

(a) Maximum credible oil spill on water

The maximum credible oil spill volume of a newly-built water transportation engineering construction project can be determined based on the overall volume of the total leakage of cargo oil or marine fuel oil carried by the design representative ship type. This terminal has a design ship type of a 50,000-ton class bulk carrier with a total fuel oil tank capacity of nearly $2200 \mathrm{~m}^{3}$. Under the oil load rate of $80 \%$, the total fuel oil is calculated as $2200 \mathrm{~m}^{3} \times 80 \% \times 0.991 \mathrm{t} / \mathrm{m}^{3}=1744 \mathrm{t}$. Thus, the maximum credible oil spill on the water in this terminal reaches $1744 \mathrm{t}$. (b) The maximum possible oil spill on water

The maximum possible oil spill volume of water transport engineering construction projects can be determined given the volume of a cargo oil side tank or fuel oil side tank that is set to represent the corresponding ship type. The ship type set for this terminal refers to a 50,000-ton class bulk carrier. Moreover, its cargo tanks are generally distributed symmetrically on the left and right sides of $4+4$. Afterwards, the fuel load of a single fuel side tank (at a fuel load rate of $80 \%$ ) is calculated as $1744 \div 8=218 \mathrm{t}$. For the mentioned information, the maximum possible oil spill volume of the wharf reaches $218 \mathrm{t}$.

\section{Risk Assessment of Oil Spill at Sea}

This paper employs a semi-quantitative method to determine the oil spill risk, and the specific method is determined with the risk matrix method. The risk matrix comprises accident probability and hazardous consequences. To be specific, the ordinate is the probability of an accident, and the abscissa represents the consequence of the hazard. Table 5 and Table 6 respectively list the classification of probability levels of oil spill accidents on water, and that of hazardous consequences of oil spill on water.

Table 5. Classification of probability levels of oil spill accidents on water.

\begin{tabular}{ll}
\hline Grade & Probability of accident/probability of an accident \\
\hline Very high & $\geq 1 / \leq 1$ working year \\
Higher & $0.1-1 /(1-10)$ working year \\
Medium & $0.02-0.1 /(10-50$ working year $)$ \\
Lower & $0.01-0.02 /(50-100$ working year $)$ \\
Very low & $0.001-0.01 /(100-1000$ working year $)$ \\
Extremely low & $<0.001 / 1000$ working year \\
\hline
\end{tabular}

Note: The first order of magnitude of the interval value includes the original number, the latter order of magnitude does not include the original number, the same below.

Table 6. Classification of hazardous consequences of oil spill on water.

\begin{tabular}{ll}
\hline $\begin{array}{l}\text { Hazardous } \\
\text { consequences }\end{array}$ & Classification \\
\hline $\mathrm{C} 1$ & Over 10,000 tons of oil spill, or direct economic loss of more than 1 billion RMB, or the hazardous consequence index value $\geq 20$ \\
C2 & Oil spill of 1000-10000 tons, or direct economic loss 2-10 billion RMB, or the value of the hazardous consequence index of 16-20 \\
C3 & Oil spill of 500-1000 tons, or direct economic loss 1-2 billion RMB, or the hazardous consequence index value of 12-16 \\
C4 & Oil spill of 100-500 tons, or direct economic loss of 50-100 million RMB, or the hazardous consequence index value of 8-12 \\
C5 & Oil spill of 50-100 tons, or direct economic loss of 10-50 million RMB, or the hazardous consequence index of 4-8 \\
C6 & Less than 50 tons of oil spill, or the direct economic loss of lower than 10 million RMB, or the hazardous consequence index value $<4$ \\
\hline
\end{tabular}

\subsection{Operational Ship Pollution Accident Risk Matrix}

The most likely leakage of operational ship pollution accidents at the wharf is $25.0 \mathrm{t}$, and the accident probability reaches $8.1 \times 10^{-4}$ per year. The area probably occurring is the anchorage or the waters in front of the wharf. By complying with the standards determined by the "Guidelines", the most likely operational ship pollution accidents at the wharf are located in the low-risk area of the risk matrix (Figure 5). 


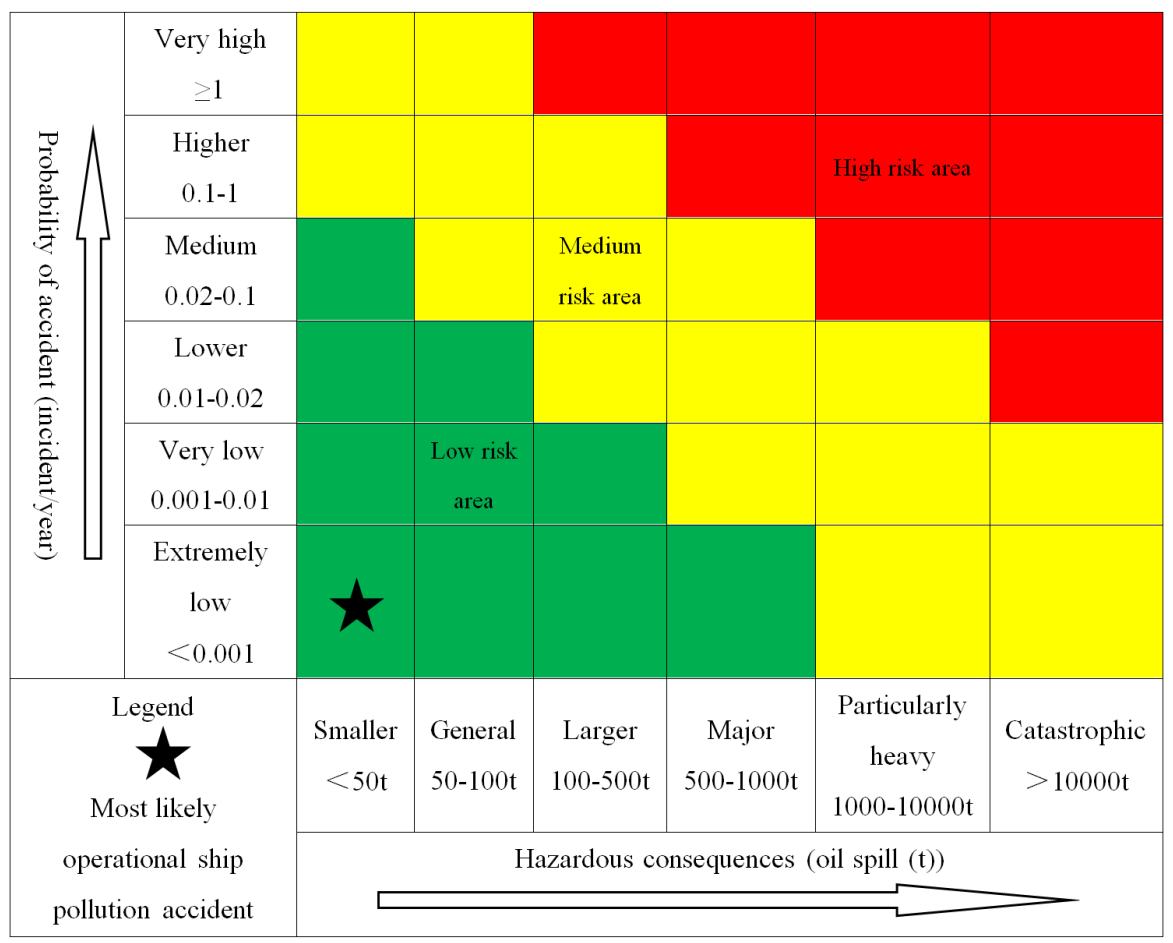

Figure 5. The most likely operational ship pollution accident risk matrix.

\subsection{Risk Matrix of Pollution Accidents from Shipwrecked Ships}

Following the calculation standard of the "Guidelines", the areas where oil spills from ships in wharf shipwreck may occur refer to the front waters of the wharf, navigation channels and anchorages, which exhibit the occurrence probability of $8.1 \times 10^{-4}$ per year. To be specific, the maximum credible oil spill accident on water reaches 1744 t, and the maximum oil spill accident on water is 218t. Abiding by the standards determined by the "Guidelines", the maximum credible oil spill pollution accident on water (1) that is most likely to occur is located in the medium-risk area of the risk matrix, and the maximum oil spill pollution accident on water (2) is located in the low-risk area of the risk matrix (Figure 6).

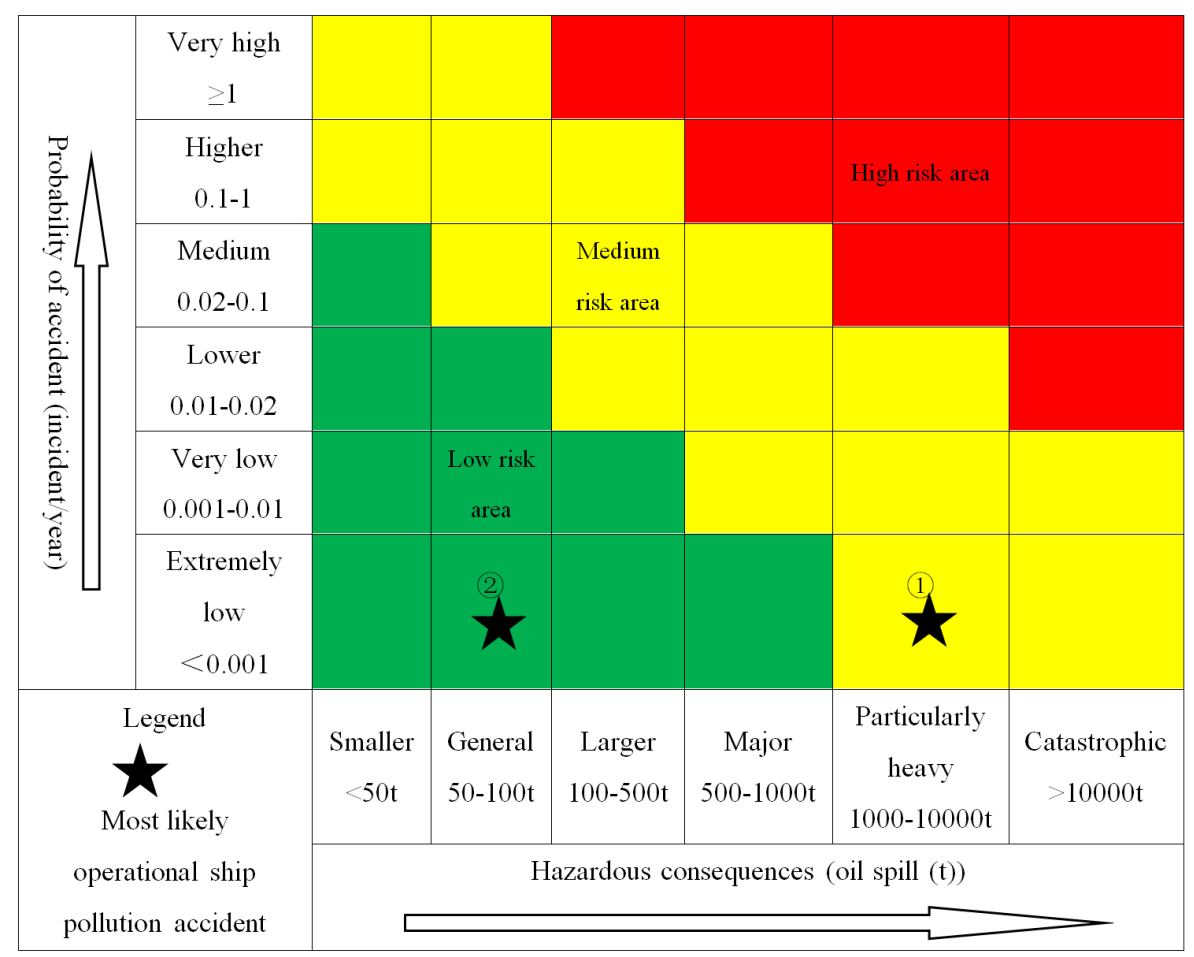

Figure 6. The risk matrix of the most likely marine pollution accidents from ships. 
When the risk matrix is adopted to analyze the accident risk semi-quantitatively, the low-risk area where the accident risk is located, the medium-risk area and the high-risk area are recognized as the negligible risk area, the tolerable risk area and the intolerable risk area, respectively. As revealed from the risk matrix analysis, operational ship pollution accidents are located in a low-risk area, and the risk of operational ship pollution accidents is negligible. The pollution accidents attributed to marine ships are located in the medium-risk area, and the risk of pollution accidents by marine ships is tolerable.

\section{Risk Reduction Countermeasures}

Given the mentioned conclusions of risk identification, risk evaluation and existing emergency response capability evaluation, relevant countermeasures were proposed by considering emergency policy, personnel and equipment to down-regulate the risk of pollution accidents. For the main risk factors, actionable preventive measures are proposed to lower the probability of ship pollution risk.

\subsection{Formulation of a Reasonable Emergency Policy}

Specific to the legal system, China joined the "1979 International Maritime Search and Rescue Convention" in 1985 [12]. However, no special national regulations have been promulgated for maritime search and rescue, and the legal positioning, rights and responsibilities, and disposal procedures of a wide range of regions when participating in search and rescue lack legal basis. When maritime search and rescue work are being conducted in various places, on one hand, the "Emergency Response Law" [13] and the "Marine Traffic Safety Law" are followed [14]; such regulations are relatively broad and exhibit relatively low operability. On the other, the search and work abide by the provincial regulations promulgated by several coastal provinces and cities, whereas numerous problems exist (e.g., low level of legislation and insufficient clarity of responsibilities). Thus, the legislative process of the national "Regulations on Search and Rescue of Human Life at Sea" should be promoted [15], as well as the integration of existing regulations and relevant international conventions.

For plans, the terminal has developed a production safety leadership group to formulate safety management systems and emergency plans regarding safety production accidents and emergency plans specific to ship oil spills, and set up corresponding organizations to tackle down the lagging construction of oil spill cleanup teams and weak overall emergency response capabilities. In the "National Emergency Response Plan for Major Marine Oil Spills", the organization and command system are clarified for accident handling, monitoring and early warning and information reporting, emergency response and disposal, as well as scheduled disposal procedures. However, the plan is being preliminarily implemented, human resources, emergency funds, technology and equipment, and communications should be enlarged to ensure that the plan is implemented in place. Besides, the linkage mechanism and press release system for major marine oil spill emergencies should be optimized.

Ship pollutants largely cover domestic sewage, oily sewage and ship garbage. To ensure the water quality of the port area, it is recommended that the port authority should proceed from the actual situation, formulate anti-pollution management regulations for ships during their stay in the port, strictly prohibit ships from discharging domestic sewage, oily sewage, washing decks, and ship garbage entering the sea while they are in the port, as an attempt to reduce the occurrence of ship pollution accidents from the root cause. The domestic sewage from ships should be temporarily stored in the port and discharged after sailing to the sea by complying with the requirements of the MARPOL Convention. Since the ship's docking time in the port may be prolonged in special scenarios, and the sanitary sewage tank cannot comply with the requirements, the port terminal should take measures to receive and process it. For oily sewage, the terminal should be equipped with an oily sewage receiving device; otherwise, a company qualified to receive ship pollutants can be entrusted to receive it. This can be determined by the shipowner. On the whole, various ship wastes that should be treated continuously or regularly in the normal operation of berthing ships include food waste, household waste, operation waste, cargo residue, operation residue, all plastics, as well as incinerator ash.

\subsection{Strengthening Personnel Emergency Training}

The publicity of the regulations on pollution prevention of the terminal should be enhanced, and the main responsibility is required to be assumed. Methods (e.g., setting up notice boards at the wharf, issuing leaflets and telegraphing the shipping company) are feasible to publicize the pollution prevention management regulations of the wharf to the berthing ships and their companies. On that basis, the ship and its crew are enabled to fully understand the relevant regulations to improve the crew's environmental awareness and jointly maintain the water environment in the port area. Besides, the corresponding punishment measures should be formulated to effectively roll out the relevant regulations. For ships violating the mentioned regulations, measures (e.g., economic penalties) can be taken to restrain the behavior of ships.

Based on the existing professional rescue team of the Salvage and Salvage Bureau of the Ministry of Transport and the characteristics of major oil spill handling at sea, a training base will be built to perform professional training for commanders, operators, and other personnel at different positions. Training should place stress on level, system, professionalism and standardization to elevate the professional and technical level of emergency personnel. Moreover, experts in a wide range of relevant professional fields should be selected and trained, and an emergency team of emergency command experts that satisfy practical should be established. A team of highly qualified professionals lays 
the basis for implementing emergency response measures. Through high-level, high-intensity, and targeted training, the overall quality of personnel is effectively improved. In this way, in the face of danger and accidents, it is possible to "come when calling, fight when coming, and win when fighting."

\subsection{Equipped with Oil Spill Emergency Equipment}

The government should initiate the construction of Ningbo's offshore oil spill emergency equipment warehouse to improve the ability to combat oil spills from ships of large tonnage. Specific to infrastructure equipment, the improvement of emergency unloading, containment and protection, recovery, temporary storage, dispersion and adsorption, and logistical support capabilities should be stressed, as well as strengthening the construction of rescue bases, vigorously propelling the construction of deep sea search and rescue, pollution removal, and navigation support capabilities, improving the spatial layout, and enhancing the construction of aircraft, especially professional fixed-wing teaching aid aircraft and long-sea search and scanning equipment. The terminal is required to be equipped with receiving devices for oily sewage, domestic sewage and domestic garbage, and sign a pollutant reception and treatment agreement with a qualified pollutant reception and treatment company to treat the pollutants received by the terminal. At this stage, the port authority has initially established an emergency equipment library (Figure 7).

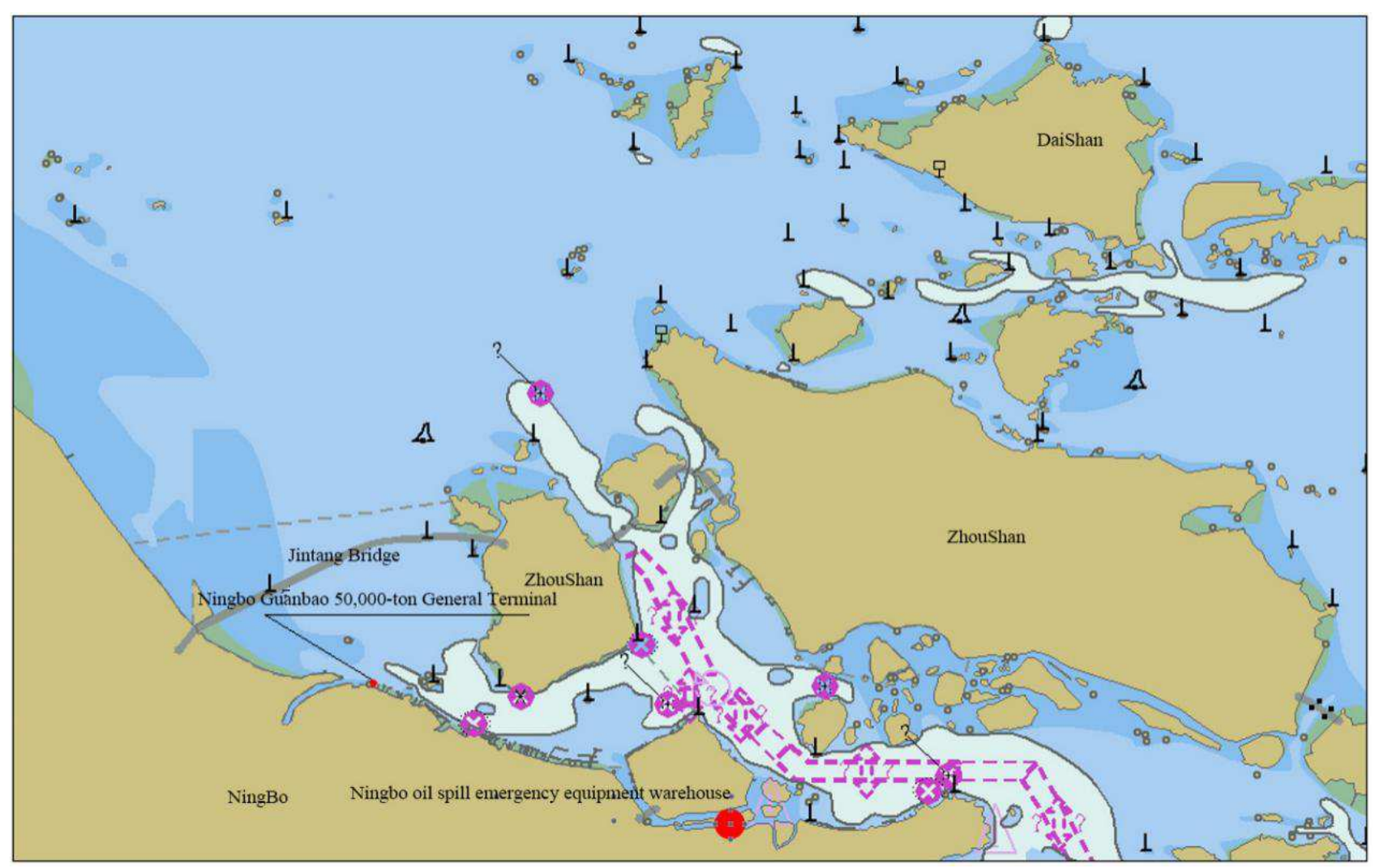

Figure 7. Schematic diagram of the location of Ningbo offshore oil spill emergency equipment warehouse.

The construction and configuration of large-scale critical ships and supporting equipment for marine emergency response should be strengthened, the level of emergency response equipment for marine hazardous chemicals should be elevated, search and rescue forces should be strengthened, and personal safety protection equipment should be increased. Besides, highly targeted emergency drills are required to organize relevant departments and units to hold major maritime search and rescue and oil spill emergency drills. For emergency technical reserves, a more in-depth communication should be developed with domestic oil spill emergency response technology research institutions, and the most cutting-edge theoretical foundation, technical capabilities, and related equipment should be mastered by holding oil spill and hazardous chemicals emergency forums.

\section{Conclusions}

By studying the marine environmental risks of ships in Ningbo Port, the conclusions are drawn below.

1) Among the major factors causing ship oil spill accidents, the riskiest factors include waterways, docks, as well as fuel; the higher risk factors are personnel, anchorage, management, meteorology, hydrology and ships; the lower risk factors include cargo. The high-risk areas for ship oil spill accidents are the front of the terminal and the entry channel.

2) Operational ship oil spill accidents mainly occurred during fuel oil refueling in the waters of the front of the 
dock or the waters of the anchorage. According to forecasts, the probability of oil spill accidents from operational ships reaches $8.1 \times 10^{-4}$ times/year, and the most likely oil spill volume is $25 \mathrm{t}$. Operational ship pollution and oil spill accidents are located in the low-risk area of the risk matrix, which are negligible; the marine accidental ship pollution and oil spill accidents are located in the middle risk area of the risk matrix, which are tolerable. However, the dock is close to the Zhoushan Islands; in the event of a pollution accident, it will more significantly impact the production of the dock and the surrounding environment.

3) Marine accidents of oil spills primarily take place during ship traffic accidents (e.g., strandings, touches, and collisions on the waters at the front of the terminal or the approaching channel). As suggested from forecasts, the probability of oil spill accidents from marine distressed ships is $8.1 \times 10^{-4}$ times/year, the most likely oil spill volume reaches $218 \mathrm{t}$, and the maximum oil spill volume is $1744 \mathrm{t}$.

4) Oily sewage, domestic sewage, and ship waste receiving equipment and facilities should be constructed at the wharf. The comprehensive control capacity of one-off oil spill removal at the terminal should reach $25 \mathrm{t}$. The wharf, i.e., the first emergency response force for oil spill accidents, should perform early disposal of oil spills.

5) In the construction of emergency response capabilities, the provision of emergency equipment, the construction of emergency teams, and the emergency management system should be optimized following the recommendations here.

The risk assessment and prediction of ship pollution provide decision support for the port to configure emergency equipment and deal with pollution accidents. How to quickly arrive at the site of accident, then reasonable and effective disposal of pollution accidents, is also an important aspect to minimize the loss of pollution accidents. In the future, we will study on the layout and optimization of the emergency equipment, and the rational scheduling of the clean-up ships, so as to improve the emergency response capacity for marine pollution accidents.

\section{References}

[1] James Salzman, Barton Thompson. American Environmental Law. in Peking University Press, 2016.
[2] Guan, Y., \& Tang, Z. The Analysis and Countermeasures Study on Oil Spills in Major World Ports. The Frontiers of Society, Science and Technology, 2020. 2 (5).

[3] Nelson, J. R., Grubesic, T. H. A repeated sampling method for oil spill impact uncertainty and interpolation. in International Journal of Disaster Risk Reduction, 2017. 22: 420-430.

[4] Ekpenyong, Nikereuwem Stephen, Udeme Sunday Udofia. Crude Oil Spills and Its Consequences on Seafoods Safety in Coastal Area of Ibeno: Akwa Ibom State. in Studies in Sociology of Science. 2015. 6 (1) pp: 16-21.

[5] Na, Song-Jin. A Consideration of the Decision-Making Efficiency Concerning the Removal of Oil Spills by Foreign Ships in the EEZ. in Journal of the Korean Society of Marine Environment \& Safety. 2019, 25 (6) pp: 698-707.

[6] Anonymous. National Emergency Plan for Maritime Search and Rescue. in China Ocean Law Review: Chinese and English, 2006 (1): 255-266.

[7] Ministry of Transport of the People's Republic of China. National Emergency Response Plan for Major Marine Oil Spills. in China Emergency Management, 2018.

[8] Anonymous. The Ministry of Transport and the National Development and Reform Commission jointly issued the "National Major Marine Oil Spill Emergency Capacity Building Plan (2015-2020)". in China Emergency Management, 2016 (2): 27-30.

[9] Jiang Kan. Oil spill risk assessment and countermeasure analysis of the 3000-ton crude oil terminal at Ningbo Port Yongfa. Dalian. in Dalian Maritime University, 2013.

[10] Li Xia. Oil spill risk analysis and prevention countermeasures of the 300,000-ton crude oil terminal in Dalian New Port. in Dalian. Dalian Maritime University, 2017.

[11] Gao Xiaowei. Research on the risk management of 300,000-ton crude oil terminal in the West Port of Yantai Port. Qingdao. in Ocean University of China, 2015.

[12] Shen Hui. Fulfill the obligations of international conventions and improve my country's search and rescue mechanism. in Heilongjiang Science and Technology Information, 2010 (05). pp: 93.

[13] General Office of the Standing Committee of the National People's Congress. in Emergency Response Law of the People's Republic of China. 2007.

[14] Maritime Traffic. Maritime Traffic Safety Law of the People's Republic of China. in Law Press, 1983.

[15] Zhou Jing, Guo Weiyi. Analysis of the nature of maritime search and rescue behavior from the perspective of administrative law. in 2008 China Dalian International Maritime Forum. 2008. 